\title{
Artemisinin Resistance in Plasmodium falciparum Malaria
}

\author{
Arjen M. Dondorp, M.D., François Nosten, M.D., Poravuth Yi, M.D., Debashish Das, M.D., \\ Aung Phae Phyo, M.D., Joel Tarning, Ph.D., Khin Maung Lwin, M.D., Frederic Ariey, M.D., \\ Warunee Hanpithakpong, Ph.D., Sue J. Lee, Ph.D., Pascal Ringwald, M.D., Kamolrat \\ Silamut, Ph.D., Mallika Imwong, Ph.D., Kesinee Chotivanich, Ph.D., Pharath Lim, M.D., \\ Trent Herdman, Ph.D., Sen Sam An, Shunmay Yeung, Ph.D., Pratap Singhasivanon, M.D., \\ Nicholas P.J. Day, D.M., Niklas Lindegardh, Ph.D., Duong Socheat, M.D., and Nicholas J. \\ White, F.R.S. \\ Mahidol Oxford Research Unit, Faculty of Tropical Medicine, Mahidol University, Bangkok \\ (A.M.D., F.N., D.D., J.T., W.H., S.J.L., K.S., M.I., K.C., T.H., S.Y., P.S., N.P.J.D., N.L., N.J.W.); \\ Shoklo Malaria Research Unit, Mae Sot (F.N., A.P.P., K.M.L.); and Family Health International, \\ Bangkok (S.S.A.) - all in Thailand; the Centre for Tropical Medicine, Churchill Hospital, Oxford, \\ United Kingdom (A.M.D., F.N., J.T., S.J.L., N.P.J.D., N.L., N.J.W.); the National Center for \\ Parasitology, Entomology, and Malaria Control (P.Y., D.S.); and Institut Pasteur du Cambodge \\ (F.A., P.L.) - both in Phnom Penh, Cambodia; and the Global Malaria Program, World Health \\ Organization, Geneva (P.R.).
}

\section{Abstract}

BACKGROUND-Artemisinin-based combination therapies are the recommended first-line treatments of falciparum malaria in all countries with endemic disease. There are recent concerns that the efficacy of such therapies has declined on the Thai-Cambodian border, historically a site of emerging antimalarial-drug resistance.

\begin{abstract}
METHODS-In two open-label, randomized trials, we compared the efficacies of two treatments for uncomplicated falciparum malaria in Pailin, western Cambodia, and Wang Pha, northwestern Thailand: oral artesunate given at a dose of $2 \mathrm{mg}$ per kilogram of body weight per day, for 7 days, and artesunate given at a dose of $4 \mathrm{mg}$ per kilogram per day, for 3 days, followed by mefloquine at two doses totaling $25 \mathrm{mg}$ per kilogram. We assessed in vitro and in vivo Plasmodium falciparum susceptibility, artesunate pharmacokinetics, and molecular markers of resistance.
\end{abstract}

RESULTS-We studied 40 patients in each of the two locations. The overall median parasite clearance times were 84 hours (interquartile range, 60 to 96) in Pailin and 48 hours (interquartile range, 36 to 66$)$ in Wang Pha $(\mathrm{P}<0.001)$. Recrudescence confirmed by means of polymerasechain-reaction assay occurred in 6 of 20 patients (30\%) receiving artesunate monotherapy and 1 of $20(5 \%)$ receiving artesunate-mefloquine therapy in Pailin, as compared with 2 of $20(10 \%)$ and 1 of $20(5 \%)$, respectively, in Wang Pha $(\mathrm{P}=0.31)$. These markedly different parasitologic responses were not explained by differences in age, artesunate or dihydroartemisinin pharmacokinetics, results of isotopic in vitro sensitivity tests, or putative molecular correlates of $P$. falciparum drug resistance (mutations or amplifications of the gene encoding a multidrug resistance protein [PfMDR1] or mutations in the gene encoding sarco-endoplasmic reticulum calcium ATPase6 [PfSERCA]). Adverse events were mild and did not differ significantly between the two treatment groups.

Copyright () 2009 Massachusetts Medical Society. All rights reserved.

Address reprint requests to Dr. Dondorp at the Faculty of Tropical Medicine, Mahidol University, 420/6 Rajvithi Rd., Bangkok 10400, Thailand, or at arjen@tropmedres.ac. .

No potential conflict of interest relevant to this article was reported. 
CONCLUSIONS $-P$. falciparum has reduced in vivo susceptibility to artesunate in western Cambodia as compared with northwestern Thailand. Resistance is characterized by slow parasite clearance in vivo without corresponding reductions on conventional in vitro susceptibility testing. Containment measures are urgently needed. (ClinicalTrials.gov number, NCT00493363, and Current Controlled Trials number, ISRCTN64835265.)

Artemisinins are established anti-malarial agents with an excellent safety profile. ${ }^{1}$ Artemisinin-based combination therapies are now recommended by the World Health Organization (WHO) as first-line treatment of uncomplicated falciparum malaria in all areas in which malaria is endemic. ${ }^{2}$ Replacing ineffective, failing treatments (chloroquine and sulfadoxine-pyrimethamine) with artemisinin-based combination therapies has reduced the morbidity and mortality associated with malaria. ${ }^{3-5}$ Parenteral artesunate is replacing quinine for the treatment of severe malaria. ${ }^{6}$ Recently, there have been signs that the efficacy of artemisinin-based combination therapy and artesunate monotherapy have declined in western Cambodia. ${ }^{7-10}$ Artemisinin resistance would be disastrous for global malaria control. To characterize treatment responses to artemisinin derivatives and provide evidence for planning containment-measure strategies, WHO and the National Malaria Control Programmes of Cambodia and Thailand established a multipartite task force. The trials reported here were conducted as part of this initiative.

\section{Methods}

\section{Study design}

We conducted two open-label, randomized, clinical, parasitologic, and pharmacokinetic studies to compare therapeutic responses to artesunate in Pailin, western Cambodia, where artemisinins have been used for more than 30 years, and at the northwestern Thai-Burmese border, a region where artemisinin-based combination therapies were first deployed ${ }^{11}$ in 1994 and remain highly effective. ${ }^{5}$ The study was monitored externally. Approval for the study design was obtained from the Ministry of Health in Cambodia, the Ethics Committee of the Faculty of Tropical Medicine of Mahidol University in Thailand, the Oxford Tropical Medicine Ethical Committee, the WHO Research Ethics Review Committee, and the Technical Review Group of the WHO Western Pacific Regional Office.

\section{Study Sites and Patients}

The studies were conducted in Pailin Referral Hospital in western Cambodia and in the Shoklo Malaria Research Unit (SMRU) clinic in Wang Pha, Tak Province, northwestern Thailand. Malaria transmission is low and seasonal in both sites. ${ }^{12}$ In Pailin, children over 5 years of age and nonpregnant adults with uncomplicated falciparum malaria (parasite density, $\geq 10,000$ per cubic millimeter of blood at the time of screening) were enrolled if written informed consent had been obtained from the patient or, if a child, from a parent or guardian. The study in Wang Pha, Thailand, started later, but the Ethics Committee of the Faculty of Tropical Medicine of Mahidol University did not approve the enrollment of children, so only nonpregnant adults and children at least 16 years of age were enrolled, after written informed consent had been provided by the patient or, if a child, by a parent or guardian. Patients with severe disease, ${ }^{2}$ coinfection, infection with other malaria species, antimalarial-drug use within 48 hours before enrollment, or known allergies to artesunate or mefloquine were excluded.

\section{Drug Therapy}

Patients were randomly assigned, in blocks of 10, to receive either artesunate (Guilin Pharmaceutical, with repacking and quality control by Sanofi-Synthelabo for distribution in Cambodia and by Atlantic for distribution in Thailand) or artesunate plus mefloquine 
(Medochemie for Cambodia and MephaPharma for Thailand). The artesunate monotherapy was administered as $2 \mathrm{mg}$ per kilogram of body weight per day, orally, for 7 days. The artesunate-mefloquine therapy was administered as artesunate at a dose of $4 \mathrm{mg}$ per kilogram per day, orally, for 3 days, plus mefloquine at a dose of $15 \mathrm{mg}$ per kilogram on day 3 and $10 \mathrm{mg}$ per kilogram on day 4.

Opaque envelopes contained the unique study numbers of the patients, with the numbers referring to numbered allocated antimalarial treatments stored in an opaque, hard-cover box. Drug administration was directly observed. If vomiting occurred within 30 minutes after administration, the full dose was repeated; if it occurred between 30 and 60 minutes after administration, half the dose was given. The use of antibiotics with antimalarial activity was avoided. All patients were hospitalized for 7 days.

\section{Clinical Procedures}

A full clinical history was obtained on admission to the hospital, and a physical examination and blood collection were carried out. Tympanic temperature was recorded every 6 hours. Fever clearance times were defined as the time to the first temperature reading of less than $37.5^{\circ} \mathrm{C}$ and the time to the start of the first 24 -hour period during which the temperature remained below $37.5^{\circ} \mathrm{C}$. Adverse events were recorded on a standard form. Parasite asexual stages and gametocyte counts were determined at $0,4,8$, and 12 hours and then every 6 hours until two consecutive slides were free of asexual parasites. The parasite clearance time was defined as the time from the start of treatment until the first negative blood smear. Parasite-reduction ratios were calculated as 100 minus the percentage reduction from the baseline level.

\section{Follow-up Evaluations}

Patients were assessed weekly until day 63 after enrollment and were advised to return if they felt unwell. Blood specimens were collected on enrollment and at the time of any recurrent parasitemia, for purposes of parasite genotyping. DNA extraction and purification were performed with the use of a standardized kit (QIAamp DNA Mini Kit, Qiagen). Amplification and analysis were performed as described previously. ${ }^{13}$ Polymorphisms in genes encoding the surface proteins of the Plasmodium falciparum merozoite (MSP-1 and MSP-2) and the glutamate-rich protein (GLURP) were compared between samples obtained before and after treatment to distinguish reinfection from recrudescence. ${ }^{14}$

Recurrent $P$. falciparum infection was treated in the artesunate-monotherapy group with artesunate at a dose of $4 \mathrm{mg}$ per kilogram per day, and in the artesunate-mefloquine group with artesunate at a dose of $6 \mathrm{mg}$ per kilogram per day, combined with doxycycline at a dose of $3.5 \mathrm{mg}$ per kilogram per day in patients 8 years of age or older or clindamycin at a dose of $10 \mathrm{mg}$ per kilogram twice a day in younger children. All these regimens were 7 days in duration.

\section{Pharmacokinetics of Artesunate and Dihydroartemisinin}

Venous-blood specimens were obtained at $0,0.25,0.5,1,1.5,2,3,4,5,6,8$, and 12 hours after the first artesunate dose. In Pailin, the samples were collected on ice in prechilled fluoride-oxalate tubes. After methodologic investigations, ${ }^{15}$ the tubes were changed to prechilled lithium-heparin tubes for the Thailand study. Samples were centrifuged at $4{ }^{\circ} \mathrm{C}$ and stored in liquid nitrogen until analysis. Plasma concentrations of artesunate and dihydroartemisinin (the active metabolite of artesunate) were measured by means of highthroughput liquid chromatography-tandem mass spectrometry after solid-phase extraction. ${ }^{16}$ Artesunate and dihydroartemisinin labeled with a stable isotope were used as internal standards. The coefficients of variation for all quality-control samples were less than 5\% at 
all drug concentrations. Pharmacokinetics were characterized through noncompartmental analysis, with the use of WinNonlin software, version 5.0 (Pharsight). Artesunate and dihydroartemisinin concentrations at the Cambodian site were multiplied by 1.09 to adjust for the different anticoagulants used at the Thai site. ${ }^{15}$ We report the observed maximum plasma concentrations of artesunate and dihydroartemisinin and the observed times to the maximum concentration.

\section{In Vitro Testing of Antimalarial-Drug Susceptibility}

In vitro testing of drug sensitivity was performed in parasites freshly obtained from the study patients at the Institute Pasteur laboratories (Phnom Penh, Cambodia) and at SMRU (Mae Sot, Thailand) by means of the standard 48-hour ${ }^{3} \mathrm{H}$-hypoxanthine uptake inhibition method. ${ }^{17}$ The laboratory-adapted strain 3D7 was used as a reference. The $50 \%$ inhibitory concentration was determined with the use of log-probit approximation, to fit the concentration-inhibition data.

\section{Molecular Markers of Antimalarial-Drug Resistance}

Copy numbers of the $P$. falciparum multidrug-resistance gene $P f M D R 1$ were assessed by means of a real-time polymerase-chain-reaction (PCR) assay (Taqman) involving previously described primers and probes. ${ }^{18}$ The $P$. falciparum $3 \mathrm{D} 7$ strain was used as an external control, and the gene encoding $\beta$-tubulin as an internal control. Polymorphisms in PfMDR1 and the gene encoding $P$. falciparum chloroquine resistance transporter (PfCRT) were assessed with the use of a PCR restriction-fragment-length-polymorphism assay or direct gene sequencing. The gene encoding sarco-endoplasmic reticulum calcium ATPase6 (PfSERCA) was amplified by means of PCR and then directly sequenced. Analysis was performed with Bioedit software.

\section{Statistical Analysis}

We calculated that we would need to enroll 40 patients at each of the two study sites to allow for the detection of a difference between the proportions of patients in whom parasitemia persists after 72 hours after the start of treatment in Wang Pha, Thailand (4\%, on the basis of historical data), and Pailin, Cambodia (expected to be at least 25\%), with a significance level of $5 \%$ and a statistical power of $80 \%$. Data were analyzed by means of Student's t-test, the chi-square test, or the Mann-Whitney U test, as appropriate. Parasite clearance times, fever clearance times, and the duration of gametocyte carriage were assessed by means of survival analysis with the use of the Kaplan-Meier method and the Wilcoxon-Breslow-Gehan test. Rates of gametocyte carriage were calculated as the total carriage time per total person-weeks of follow-up. To adjust for the higher parasite load at baseline in Pailin, the analysis was stratified according to the $\log _{10}$-normalized parasite $\operatorname{load}_{\text {, }}$ with strata of less than 5.00 and 5.00 or more. Multivariate regression was also performed, with parasite clearance time as the dependent variable and study site and baseline parasite density as independent variables. Linear regression modeling was performed with the use of serial log parasite counts to estimate the times to clearance of $50 \%$ and $90 \%$ of the parasite load for each patient. All analyses were performed with the use of Stata software, version 10 (StataCorp).

\section{Results}

Between June 2007 and May 2008, a total of 80 patients were enrolled: 40 in Pailin, of whom 11 (28\%) were under 16 years of age, and 40 in Wang Pha, where children were not enrolled (Fig. 1 and Table 1, and Table S1 in the Supplementary Appendix, available with the full text of this article at NEJM.org). The number of days of fever before enrollment was 
similar in Pailin (median, 3 days; range, 1.5 to 8 ) and in Wang Pha (median, 2 days; range, 1 to 6) $(\mathrm{P}=0.21)$.

\section{Parasitologic and Clinical Responses}

Parasite clearance was markedly slower in Pailin (Table 2), with a median parasite clearance time for both Pailin treatment groups combined of 84 hours (interquartile range, 60 to 96), as compared with 48 hours (interquartile range, 36 to 66$)$ in both Wang Pha groups $(\mathrm{P}<0.001)$. After the start of treatment in Pailin, 73\% of patients had parasitemia at 48 hours, 55\% at 72 hours, and 20\% at 96 hours; the corresponding percentages in Wang Pha were 45\%, 8\%, and $3 \%(\mathrm{P}<0.001)$. In Pailin, the parasite density at baseline was similar in children under 16 years of age (geometric mean, 50,046 per cubic millimeter; 95\% confidence interval [CI], 22,767 to 110,007 ) and in children at least 16 years of age and adults (geometric mean, 71,366 per cubic millimeter; $95 \%$ CI, 49,614 to 102,654) $(\mathrm{P}=0.33)$. In Pailin, the median parasite clearance time among the 11 children was 78 hours (interquartile range, 60 to 96), as compared with 84 hours (interquartile range, 66 to 96) among the 29 adults and children at least 16 years of age $(\mathrm{P}=0.67)$. To assess whether exclusion of children from the Wang Pha, Thailand, study influenced the results, data from the Cambodian children were excluded from the analysis; the difference in parasite clearance times between the two study sites remained significant $(\mathrm{P}<0.001)$ (Table S2 in the Supplementary Appendix). We also compared the parasite clearance times as calculated on the basis of daily parasite counts in 3264 patients (1996 adults and children at least 16 years of age, and 1268 children under 16 years of age) in the Thailand study area between 1995 and 2007, as well as the times as calculated on the basis of counts every 6 hours in 1214 patients with hyperparasitemia (449 adults and children at least 16 years of age, and 765 children under 16 years of age) who were treated with artesunate-containing regimens. After adjustment for parasitemia, study location, and year of admission, there was no significant difference for children under 16 years of age as compared with adults and children at least 16 years of age in parasite clearance times $(\mathrm{P}>0.20$ for all comparisons).

The difference in parasite clearance times also remained significant when the analysis was stratified according to the $\log _{10}$-normalized parasite density on admission $(\mathrm{P}=0.008)$. Further analysis involving linear regression, adjusted for baseline parasite density, showed that site was a significant independent predictor of the time to parasite clearance, whether children were included in the model (coefficient, $18.1 ; 95 \% \mathrm{CI}, 8.9$ to $27.2 ; \mathrm{P}<0.001$ ) or excluded from the model (coefficient, $18.7 ; 95 \% \mathrm{CI}, 8.0$ to $29.4 ; \mathrm{P}=0.001$ ). Other measures of parasite reduction that are less dependent on the initial parasite load, including the parasite-reduction ratios after 24 and 48 hours and the slope of the $\log _{10}$-normalized parasite clearance over time, were also markedly different between the study sites (Table 2 and Fig. 2).

In Pailin, there was no evident dose-response relationship for artesunate: the median parasite clearance time was 84 hours (interquartile range, 54 to 96) for the dose of $2 \mathrm{mg}$ per kilogram and 72 hours (interquartile range, 60 to 96) for the dose of $4 \mathrm{mg}$ per kilogram ( $\mathrm{P}=$ 0.61). In contrast, in Wang Pha, patients treated with artesunate at a dose of $4 \mathrm{mg}$ per kilogram had faster parasite clearance (median, 48 hours; interquartile range, 30 to 54 ) than those treated with artesunate at a dose of $2 \mathrm{mg}$ per kilogram (median, 54; interquartile range, 42 to 72$)(\mathrm{P}=0.02)$ (Table 2$)$.

Fever clearance times did not differ significantly between the two study sites (Table 2). Early treatment failure, defined as parasitemia and fever persisting for more than 3 days ( $\geq 72$ hours) after the start of treatment, ${ }^{2}$ occurred in 3 of the 40 patients (8\%) in Pailin, as compared with none in Wang $\mathrm{Pha}(\mathrm{P}=0.20)$. In the artesunate-monotherapy group, late parasitologic failure (defined as PCR-confirmed recrudescence of $P$. falciparum infection $>7$ 
days after the start of treatment $)^{2}$ occurred in 6 of the 20 patients (30\%) in Pailin after a median of 28 days (range, 21 to 35) and in 2 of the 20 patients (10\%) in Wang Pha, after 21 days for both patients. In the artesunate-mefloquine group, there were no occurrences of early treatment failure, and late parasitologic failure occurred in 1 of the 20 patients (5\%) at each site, after 49 days in Pailin and 34 days in Wang Pha. Reinfection was more common in Wang Pha than in Pailin $(\mathrm{P}=0.001)$ (Table 2$)$. Recurrent infection with $P$. vivax was common at both study sites. The median duration of patent gametocytemia per person-weeks of follow-up was 0.06 weeks (95\% CI, 0.05 to 0.07 ) in Wang Pha and 0.07 weeks (95\% CI, 0.06 to 0.08$)$ in Pailin $(\mathrm{P}=0.13)$. The duration of gametocyte carriage in patients who had gametocytemia at any time also did not differ significantly between the sites (Table 2).

The number of patients reporting an adverse event did not differ significantly between the two treatment groups (Table S3 in the Supplementary Appendix). Dizziness, joint pain, muscle pain, and sleepiness were more common in Wang Pha, whereas nausea, abdominal pain, and fatigue were reported more frequently in Pailin. No serious adverse events were observed.

\section{Pharmacokinetics}

Body-weight-normalized doses of the study drugs were similar at the two study sites. Plasma-concentration profiles of artesunate and dihydroartemisinin, and the pharmacokinetic variables derived from them, were generally similar at the two sites, although the areas under the concentration-time curves were slightly greater in Pailin (Table 3). There was no significant correlation between the maximum concentration of artesunate or dihydroartemisinin, or the area under the concentration-time curve, and measures of parasite clearance (parasite clearance time and parasite-reduction ratios after 24 and 48 hours) or the risk of treatment failure (Fig. S1 in the Supplementary Appendix). Exclusion of children from the analysis did not affect these findings.

\section{In Vitro Sensitivity Testing}

Reliable fitting of the hypoxanthine-uptake curves for artesunate and dihydroartemisinin was possible for 18 of the 40 patients for both drugs in Pailin and 32 of 40 patients and 30 of 40 patients, respectively, in Wang Pha. The median 50\% inhibitory concentration of artesunate in Pailin was $1.9 \mathrm{nM}$ (interquartile range, 1.3 to 3.4), as compared with $3.2 \mathrm{nM}$ (interquartile range, 1.7 to 4.1$)$ in Wang Pha $(\mathrm{P}=0.07)$ and $2.7 \mathrm{nM}$ for the reference strain 3D7. The median 50\% inhibitory concentration of artesunate in Pailin was $1.9 \mathrm{nM}$ (interquartile range, 1.3 to 3.4 ), as compared with $3.2 \mathrm{nM}$ (interquartile range, 1.7 to 4.1 ) in Wang Pha $(\mathrm{P}=0.07)$ and $2.7 \mathrm{nM}$ for the reference strain 3D7. The median 50\% inhibitory concentration of dihydroartemisinin in Pailin was $2.3 \mathrm{nM}$ (interquartile range, 1.1 to 3.2), as compared with $1.5 \mathrm{nM}$ (interquartile range, 0.7 to 2.2$)$ in Wang Pha $(\mathrm{P}=0.04)$ and $2.3 \mathrm{nM}$ for the reference 3D7 (Fig. 3). There were no significant correlations between the 50\% inhibitory concentration of artesunate or dihydroartemisinin and the parasite clearance times in Pailin (artesunate: $\mathrm{r}=0.07, \mathrm{P}=0.70$; dihydroartemisinin: $\mathrm{r}=0.19, \mathrm{P}=0.33$ ) or Wang Pha (artesunate: $\mathrm{r}=0.20, \mathrm{P}=0.44$; dihydroartemisinin: $\mathrm{r}=0.28, \mathrm{P}=0.23$ ). The $50 \%$ inhibitory concentrations of mefloquine and chloroquine did not differ significantly between the two study sites (Fig. 3).

\section{Molecular Markers of Resistance}

In Pailin, 38 of 40 patients (95\%) had parasites that contained single copies of PfMDR1, and the 2 remaining patients (5\%) had two copies, both associated with 50\% inhibitory concentrations of mefloquine exceeding $150 \mathrm{nM}$. In Wang Pha, 18 of the 40 patients (45\%) had isolates that contained multiple copies of PfMDR1 (median, 2; range, 1 to 3; $\mathrm{P}<0.001$ ). We did not detect any point mutations in the PfMDR1 gene at positions N86Y, S1034C, 
N1042D, and D1246Y, but the mutant codon Y184F was found in isolates from 32 of the 40 patients (80\%) in Pailin and 12 of the 40 patients (30\%) in Wang Pha. All parasites had the K76T mutation in the PfCRT gene. Full-length sequencing of the PfSERCA gene revealed sporadic point mutations noted as I89T (in isolates from 5 of 50 patients), N465S (in isolates from 7 of 44 patients), and E847K (in isolates from 1 of 45 patients), with similar frequencies at the two study sites. The number of insertion-deletion mutations of T-A repeats located in the intron region of the gene (nt3621-3671) varied among parasites (range, 10 to 19) but did not differ between the two sites. The PfSERCA L263E and S769 N polymorphisms, proposed to confer artemisinin resistance, were not detected.

\section{Discussion}

Our study shows that $P$. falciparum parasites from patients in Pailin, western Cambodia, had significantly reduced in vivo susceptibility to artesunate, as compared with parasites from northwestern Thailand - or indeed, apparently, anywhere else in the world. Artesunate resistance was characterized by a markedly prolonged time to parasite clearance, with relatively little heterogeneity among patients. These reduced parasitologic responses could not be explained by pharmacokinetic or other host factors.

The principal pharmacodynamic advantage of using artemisinins rather than other antimalarial drugs is that they accelerate parasite clearance ${ }^{1}$ by clearing young, circulating, ring-stage parasites and preventing the further maturation and sequestration of these parasites. ${ }^{19,20}$ This effect accounts for the rapidity of the therapeutic response, its lifesaving benefit in patients with severe malaria, and the notable gametocytocidal activity of the drugs. A few cases of reduced efficacy of artemisinin-based combination therapy have been reported previously. Most of these cases can be explained by the counterfeit nature of the drugs tested. ${ }^{21}$ In 2002-2003, decreased in vitro sensitivity of $P$. falciparum to artemether was reported in French Guiana (but not in Cambodia) and was associated with the S769N mutation in the PfSERCA gene. ${ }^{22,23}$ There were no clinical correlates. In our study, there was no consistent pattern of PfSERCA mutations, despite clear evidence of in vivo artesunate resistance.

Monitoring in western Cambodia has shown a decline in the efficacy of artemisinin-based combination therapy in recent years, but the relative contributions of resistance to artemisinin, the partner drug, and other factors have been un-clear. ${ }^{7-10,24}$ In a recent Cambodian study, increased numbers of copies of the PfMDR1 gene, a well-established cause of mefloquine resistance, ${ }^{18}$ was associated with high failure rates with artesunatemefloquine therapy ${ }^{7,25}$ In the current study, despite artesunate resistance, the efficacy of artesunate-mefloquine use was excellent in Pailin (63-day cure rate, 95\%), presumably because $95 \%$ of parasite isolates had a single PfMDR1 copy. PfMDR1 amplification also causes a small decrease in artemisinin susceptibility, ${ }^{18}$ but neither this nor any other molecular markers of antimalarial-drug resistance that we evaluated could explain the resistance to artesunate in Pailin.

There was an unexpected discrepancy between the slow clinical and parasitologic responses in Pailin and the relatively normal in vitro susceptibility. The discrepancy can be explained by the reduced susceptibility of the young, ring-form parasites as compared with the more mature trophozoites and schizonts. Currently available in vitro susceptibility tests assess drug exposure over the entire parasite cycle; therefore, the results would be relatively unaffected if only part of the cycle were affected by the mechanism underlying the resistance. Previous studies have not indicated significant differences in parasitologic responses within the dose range that we evaluated ( 2 to $4 \mathrm{mg}$ per kilogram per day). ${ }^{26} \mathrm{~A}$ concentration-effect relationship was evident in Wang Pha but not in Pailin, suggesting that 
a small shift to the right along the dose-response curve may also have occurred at the ThaiBurmese border. ${ }^{27}$

Chloroquine and sulfadoxine-pyrimethamine resistance in $P$. falciparum emerged in the late 1950s and 1960s on the Thai-Cambodian border and spread across Asia and then Africa, contributing to millions of deaths from malaria. ${ }^{28,29}$ Artemisinins have been available as monotherapies in western Cambodia for more than 30 years, in a variety of forms and doses, whereas in most countries (other than China, where they were discovered), they have been a relatively recent introduction. ${ }^{1}$ Despite the early implementation of an active malaria-control program by the Ministry of Health of Cambodia, including the introduction of artemisininbased combination therapies in 2001, a recent survey showed that $78 \%$ of artemisinin use in western Cambodia consisted of monotherapy provided through the private sector. ${ }^{30}$ The extended period of often-suboptimal use, and the genetic background of parasites from this region, ${ }^{31}$ might have contributed to the emergence and subsequent spread of these new artemisinin-resistant parasites in western Cambodia. In contrast, artemisinin derivatives have been used almost exclusively in combination with mefloquine on the Thai-Burmese border, where parasitologic responses to artemisinins remain good, even after 15 years of intensive use. ${ }^{27}$ Measures for containment are now urgently needed to limit the spread of these parasites from western Cambodia and to prevent a major threat to current plans for eliminating malaria.

\section{Acknowledgments}

Supported by grants from the Wellcome Trust of Great Britain (Major Overseas Programme-Thailand Unit Core Grant) and the Li Ka Shing Foundation (B9RMXT0-2) and by the WHO through grants from the Bill and Melinda Gates Foundation (48821) and the U.S. Agency for International Development (umbrella grant AAGG-00-99-00005).

We thank the patients for their participation; all staff members of the Pailin Referral Hospital and the SMRU clinic for their dedicated care for the patients and assistance in the study; Tim Anderson for help with the in vitro sensitivity testing; the Village Malaria Workers in Pailin for their collaboration; and Vasee Moorthy, Golam Kibria, Mark Fukuda, and George Watt for help in executing and organizing the trial in Pailin.

\section{References}

1. White NJ. Qinghaosu (artemisinin): the price of success. Science. 2008; 320:330-4. [PubMed: 18420924]

2. WHO guidelines for the treatment of malaria. World Health Organization; Geneva: 2006.

3. Barnes KI, Durrheim DN, Little F, et al. Effect of artemether-lumefantrine policy and improved vector control on malaria burden in KwaZulu-Natal, South Africa. PLoS Med. 2005; 2(11):e330. [PubMed: 16187798]

4. Bhattarai A, Ali AS, Kachur SP, et al. Impact of artemisinin-based combination therapy and insecticide-treated nets on malaria burden in Zanzibar. PLoS Med. 2007; 4(11):e309. [PubMed: 17988171]

5. Carrara VI, Sirilak S, Thonglairuam J, et al. Deployment of early diagnosis and mefloquineartesunate treatment of falciparum malaria in Thailand: the Tak Malaria Initiative. PLoS Med. 2006; 3(6):e183. [PubMed: 16719547]

6. Dondorp A, Nosten F, Stepniewska K, et al. Artesunate versus quinine for treatment of severe falciparum malaria: a randomised trial. Lancet. 2005; 366:717-25. [PubMed: 16125588]

7. Alker AP, Lim P, Sem R, et al. Pfmdr1 and in vivo resistance to artesunate-mefloquine in falciparum malaria on the Cambodian-Thai border. Am J Trop Med Hyg. 2007; 76:641-7. [PubMed: 17426163]

8. Denis MB, Tsuyuoka R, Poravuth Y, et al. Surveillance of the efficacy of artesunate and mefloquine combination for the treatment of uncomplicated falciparum malaria in Cambodia. Trop Med Int Health. 2006; 11:1360-6. [PubMed: 16930257] 
9. Denis MB, Tsuyuoka R, Lim P, et al. Efficacy of artemether-lumefantrine for the treatment of uncomplicated falciparum malaria in northwest Cambodia. Trop Med Int Health. 2006; 11:1800-7. [PubMed: 17176344]

10. Noedl H, Se Y, Schaecher K, Smith BL, Socheat D, Fukuda MM. Evidence of artemisinin-resistant malaria in western Cam bodia. N Engl J Med. 2008; 359:2619-20. [PubMed: 19064625]

11. Nosten F, Luxemburger C, ter Kuile FO, et al. Treatment of multidrug-resistant Plasmodium falciparum malaria with 3-day artesunate-mefloquine combination. J Infect Dis. 1994; 170:971-7. [PubMed: 7930743] J Infect Dis. 1995; 171:519.

12. Luxemburger C, Thwai KL, White NJ, et al. The epidemiology of malaria in a Karen population on the western border of Thailand. Trans R Soc Trop Med Hyg. 1996; 90:105-11. [PubMed: 8761562]

13. Snounou G, Zhu X, Siripoon N, et al. Biased distribution of msp1 and msp2 allelic variants in Plasmodium falciparum populations in Thailand. Trans R Soc Trop Med Hyg. 1999; 93:369-74. [PubMed: 10674079] Trans R Soc Trop Med Hyg. 2000; 94:65.

14. Genotyping to identify parasite populations. World Health Organization; Geneva: 2008.

15. Lindegardh N, Hanpithakpong W, Kamanikom B, et al. Major pitfalls in the measurement of artemisinin derivatives in plasma in clinical studies. J Chromatogr B Analyt Technol Biomed Life Sci. 2008; 876:54-60.

16. Lindegardh N, Dondorp AM, Singhasivanon P, White NJ, Day NP. Validation and application of a liquid chromatographic-mass spectrometric method for determination of artesunate in pharmaceutical samples. J Pharm Biomed Anal. 2007; 45:149-53. [PubMed: 17553648]

17. Webster HK, Boudreau EF, Pavanand K, Yongvanitchit K, Pang LW. Antimalarial drug susceptibility testing of Plasmodium falciparum in Thailand using a microdilution radioisotope method. Am J Trop Med Hyg. 1985; 34:228-35. [PubMed: 3885770]

18. Price RN, Uhlemann AC, Brockman A, et al. Mefloquine resistance in Plasmodium falciparum and increased pfmdr1 gene copy number. Lancet. 2004; 364:438-47. [PubMed: 15288742]

19. ter Kuile F, White NJ, Holloway P, Pasvol G, Krishna S. Plasmodium falciparum: in vitro studies of the pharmacodynamic properties of drugs used for the treatment of severe malaria. Exp Parasitol. 1993; 76:85-95. [PubMed: 8467901]

20. Udomsangpetch R, Pipitaporn B, Krishna S, et al. Antimalarial drugs reduce cytoadherence and rosetting of Plasmodium falciparum. J Infect Dis. 1996; 173:691-8. [PubMed: 8627034]

21. Keoluangkhot V, Green MD, Nyadong L, Fernández FM, Mayxay M, Newton PN. Impaired clinical response in a patient with uncomplicated falciparum malaria who received poor-quality and underdosed intramuscular artemether. Am J Trop Med Hyg. 2008; 78:552-5. [PubMed: 18385347]

22. Jambou R, Legrand E, Niang M, et al. Resistance of Plasmodium falciparum field isolates to invitro artemether and point mutations of the SERCA-type PfATPase6. Lancet. 2005; 366:1960-3. [PubMed: 16325698]

23. Eckstein-Ludwig U, Webb RJ, Van Goethem ID, et al. Artemisinins target the SERCA of Plasmodium falciparum. Nature. 2003; 424:957-61. [PubMed: 12931192]

24. Ashley EA, Stepniewska K, Lindegårdh N, et al. How much fat is necessary to optimize lumefantrine oral bioavailability? Trop Med Int Health. 2007; 12:195-200. [PubMed: 17300625]

25. Wongsrichanalai C, Meshnick SR. Declining artesunate-mefloquine efficacy against falciparum malaria on the Cambodia-Thailand border. Emerg Infect Dis. 2008; 14:716-9. [PubMed: 18439351]

26. Angus BJ, Thaiaporn I, Chanthapadith K, Suputtamongkol Y, White NJ. Oral artesunate doseresponse relationship in acute falciparum malaria. Antimicrob Agents Chemother. 2002; 46:77882. [PubMed: 11850261]

27. Carrara VI, Zwang J, Ashley EA, et al. Changes in the treatment responses to artesunatemefloquine on the northwestern border of Thailand during 13 years of continuous deployment. PLoS One. 2009; 4(2):e4551. [PubMed: 19234601]

28. Roper C, Pearce R, Nair S, Sharp B, Nosten F, Anderson T. Intercontinental spread of pyrimethamine-resistant malaria. Science. 2004; 305:1124. [PubMed: 15326348] 
29. Verdrager J. Epidemiology of the emergence and spread of drug-resistant falciparum malaria in South-East Asia and Australasia. J Trop Med Hyg. 1986; 89:277-89. [PubMed: 3543384]

30. Yeung S, Van Damme W, Socheat D, White NJ, Mills A. Access to artemisinin combination therapy for malaria in remote areas of Cambodia. Malar J. 2008; 7:96. [PubMed: 18510724]

31. Rathod PK, McErlean T, Lee PC. Variations in frequencies of drug resistance in Plasmodium falciparum. Proc Natl Acad Sci U S A. 1997; 94:9389-93. [PubMed: 9256492] 


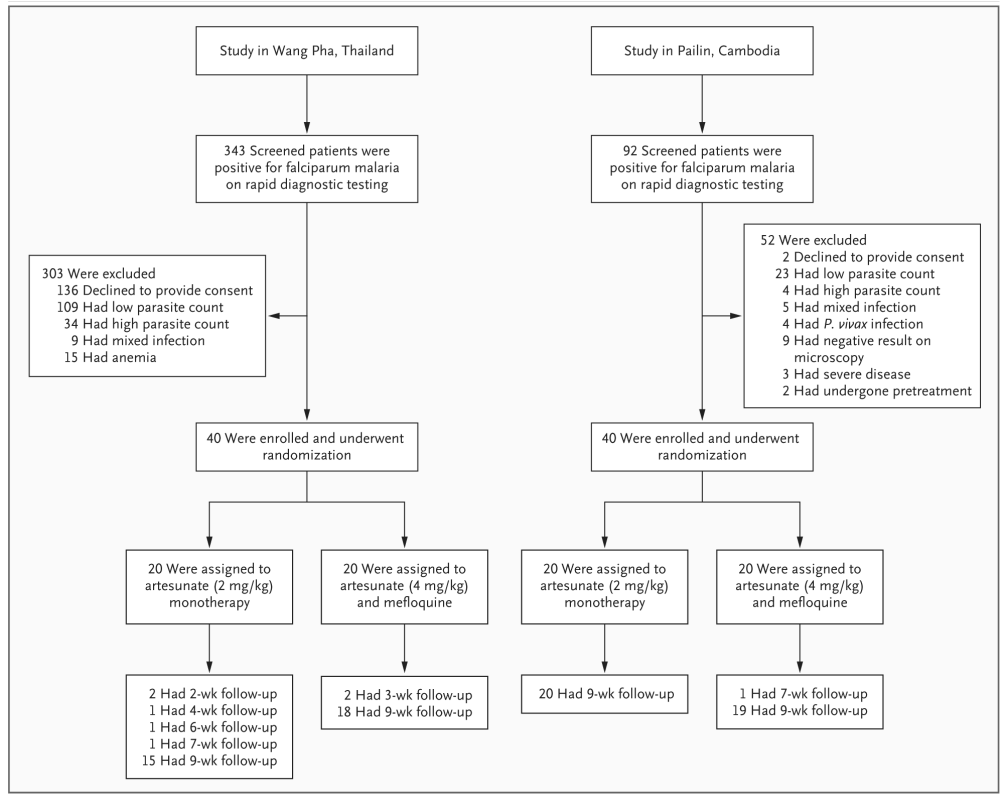

Figure 1. Enrollment, Randomization, and Follow-up of the Patients in the Two Studies Mixed infection was infection with Plasmodium vivax and $P$. falciparum. 


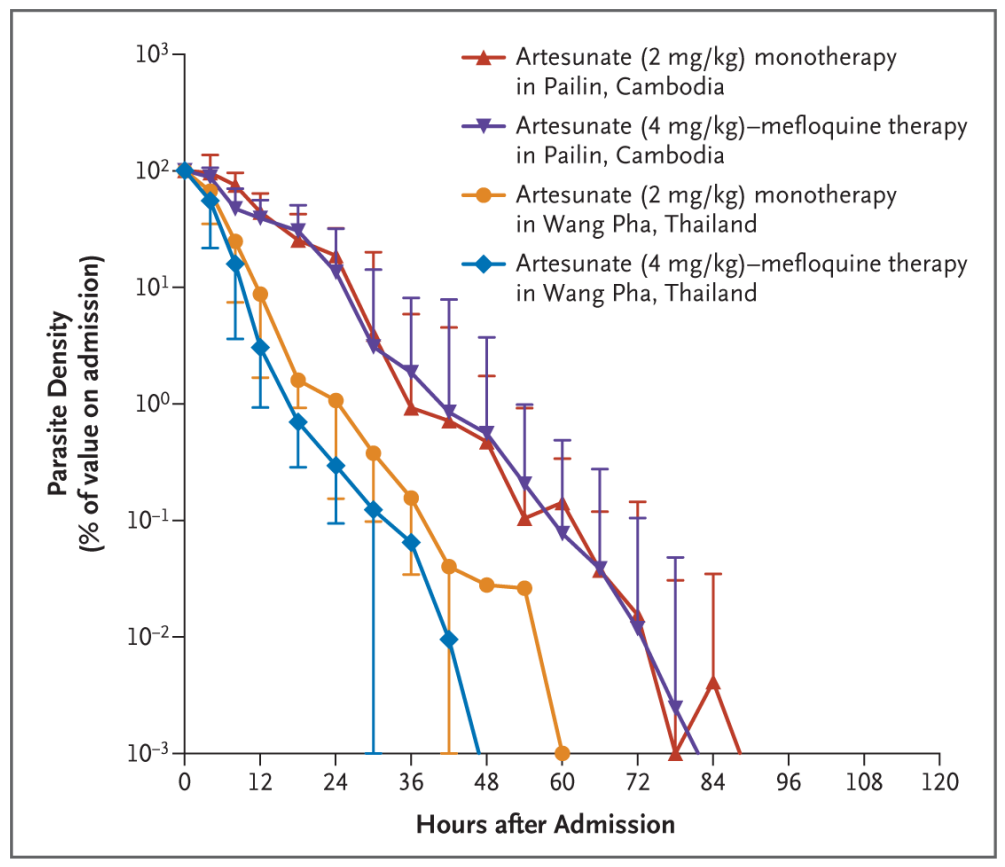

Figure 2. Parasite Clearance Curves

The data are $\log _{10}$-normalized median parasite densities over time among the 20 patients in each treatment group. The $\mathrm{T}$ bars indicate half of the interquartile ranges. Artesunate monotherapy consisted of artesunate at a dose of $2 \mathrm{mg}$ per kilogram of body weight for 7 days. Artesunate-mefloquine therapy consisted of artesunate at a dose of $4 \mathrm{mg}$ per kilogram for 3 days followed by mefloquine at a dose of $15 \mathrm{mg}$ per kilogram on day 3 after admission and $10 \mathrm{mg}$ per kilogram on day 4 after admission. 


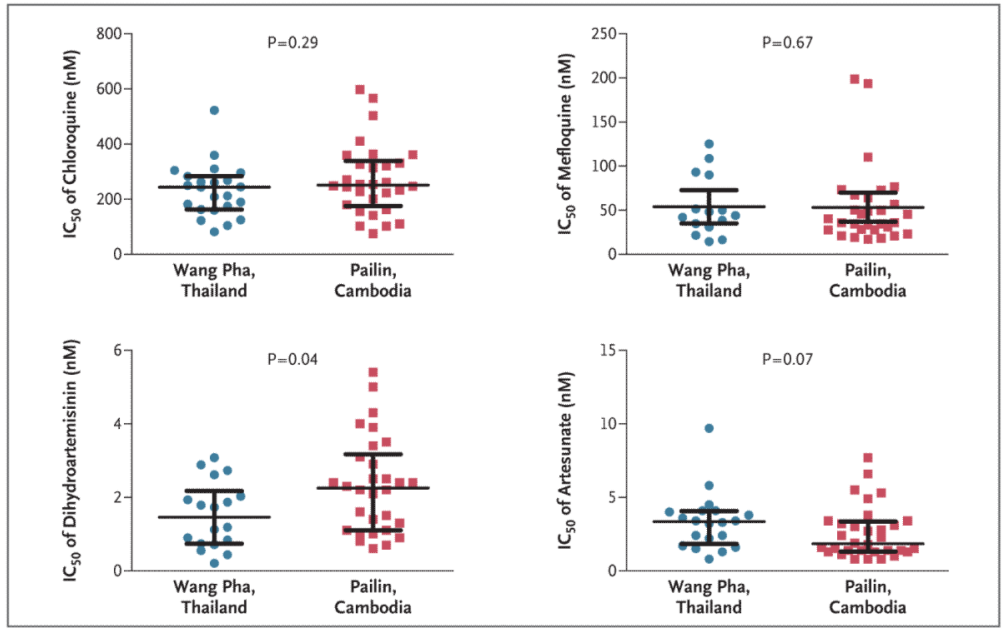

Figure 3. The 50\% Inhibitory Concentration $\left(\mathrm{IC}_{50}\right)$ for Plasmodium falciparum, According to Antimalarial Drug

The panels show the concentrations of chloroquine, mefloquine, dihydroartemisinin, and artesunate resulting in the inhibition of hypoxanthine uptake by $50 \%$ after 48 hours of in vitro culture of freshly isolated $P$. falciparum from the study patients. The horizontal lines are the medians; the I bars represent the interquartile ranges. 


\section{Table 1}

Baseline Characteristics of the Study Patients, According to Location. *

\begin{tabular}{|c|c|c|c|c|c|}
\hline \multirow[t]{2}{*}{ Characteristic } & \multicolumn{2}{|c|}{ Wang Pha, Thailand } & \multicolumn{2}{|c|}{ Pailin, Cambodia } & \multirow{2}{*}{$\begin{array}{c}\text { P Value for Wang Pha } \\
\text { vs. Pailin }\end{array}$} \\
\hline & $\begin{array}{c}\text { Artesunate } \\
\text { Monotherapy } \\
(\mathbf{N}=\mathbf{2 0})\end{array}$ & $\begin{array}{l}\text { Artesunate- } \\
\text { Mefloquine } \\
(\mathbf{N}=\mathbf{2 0})\end{array}$ & $\begin{array}{c}\text { Artesunate } \\
\text { Monotherapy } \\
(\mathbf{N}=\mathbf{2 0})\end{array}$ & $\begin{array}{c}\text { Artesunate- } \\
\text { Mefloquine } \\
(\mathbf{N}=\mathbf{2 0})\end{array}$ & \\
\hline Male sex - no. $(\%)$ & $19(95)$ & $20(100)$ & $15(75)$ & $16(80)$ & 0.01 \\
\hline Weight $-\mathrm{kg}$ & & & & & $0.001^{\dagger}$ \\
\hline Median & 55 & 51 & 47 & 47 & \\
\hline Range & $35-66$ & $39-59$ & $21-60$ & $21-62$ & \\
\hline Age $-\mathrm{yr}$ & & & & & 0.008 \\
\hline Mean & 31 & 30 & 27 & 22 & \\
\hline $95 \% \mathrm{CI}$ & $28-35$ & $26-34$ & $21-33$ & $16-27$ & \\
\hline Temperature $-{ }^{\circ} \mathrm{C}$ & & & & & $<0.001$ \\
\hline Median & 37.9 & 37.3 & 38.5 & 38.5 & \\
\hline $95 \% \mathrm{CI}$ & $37.6-38.3$ & $36.9-37.7$ & $38.1-38.9$ & $38.1-38.9$ & \\
\hline Hemoglobin $-\mathrm{g} / \mathrm{dl}$ & & & & & 0.21 \\
\hline Median & 12.5 & 12.4 & 11.8 & 12.0 & \\
\hline $95 \% \mathrm{CI}$ & $11.7-13.3$ & $11.6-13.3$ & $10.8-12.8$ & $10.9-13.1$ & \\
\hline White-cell count $-\times 10^{-3} / \mathrm{mm}^{3}$ & & & & & $0.71^{\dagger}$ \\
\hline Median & 5.6 & 5.8 & 5.3 & 6.2 & \\
\hline Range & $2.0-13.4$ & $2.8-12.2$ & $3.7-8.9$ & $3.3-11.9$ & \\
\hline Platelet count $-\times 10^{-3} / \mathrm{mm}^{3}$ & & & & & $0.19^{\dagger}$ \\
\hline Median & 121 & 104 & 82 & 114 & \\
\hline Range & $47-410$ & $29-357$ & $17-357$ & $40-383$ & \\
\hline Glucose - mg/dl & & & & & $<0.001^{\dagger}$ \\
\hline Median & 116 & 108 & 98 & 97 & \\
\hline Range & $96-169$ & $89-197$ & $74-186$ & $74-184$ & \\
\hline Creatinine $-\mathrm{mg} / \mathrm{dl}$ & & & & & $0.02^{\dagger}$ \\
\hline Median & 0.98 & 0.97 & 0.85 & 0.81 & \\
\hline $95 \% \mathrm{CI}$ & $0.90-1.06$ & $0.89-1.04$ & $0.75-0.95$ & $0.66-0.95$ & \\
\hline Bilirubin $-\mathrm{mg} / \mathrm{dl}$ & & & & & $<0.001$ \\
\hline Geometric mean & 1.00 & 0.94 & 1.53 & 1.57 & \\
\hline $95 \% \mathrm{CI}$ & $0.74-1.34$ & $0.75-1.19$ & $1.26-1.87$ & $1.29-1.92$ & \\
\hline Alanine aminotransferase - U/liter & & & & & $0.15^{\dagger}$ \\
\hline Median & 24 & 27 & 26 & 17 & \\
\hline Range & $7-110$ & $7-50$ & $8-80$ & $6-40$ & \\
\hline Aspartate aminotransferase - U/liter & & & & & $<0.001^{\dagger}$ \\
\hline Median & 25 & 30 & 45 & 38 & \\
\hline
\end{tabular}




\begin{tabular}{|c|c|c|c|c|c|}
\hline \multirow[t]{2}{*}{ Characteristic } & \multicolumn{2}{|c|}{ Wang Pha, Thailand } & \multicolumn{2}{|c|}{ Pailin, Cambodia } & \multirow{2}{*}{$\begin{array}{c}\text { P Value for Wang Pha } \\
\text { vs. Pailin }\end{array}$} \\
\hline & $\begin{array}{l}\text { Artesunate } \\
\text { Monotherapy } \\
(\mathbf{N}=\mathbf{2 0})\end{array}$ & $\begin{array}{l}\text { Artesunate- } \\
\text { Mefloquine } \\
(\mathbf{N}=\mathbf{2 0})\end{array}$ & $\begin{array}{l}\text { Artesunate } \\
\text { Monotherapy } \\
(\mathbf{N}=\mathbf{2 0})\end{array}$ & $\begin{array}{l}\text { Artesunate- } \\
\text { Mefloquine } \\
(\mathbf{N}=\mathbf{2 0})\end{array}$ & \\
\hline Range & $12-130$ & $15-51$ & $30-149$ & $29-65$ & \\
\hline Alkaline phosphatase - U/liter & & & & & $<0.001^{\dagger}$ \\
\hline Median & 68 & 79 & 108 & 92 & \\
\hline Range & $33-148$ & $43-118$ & $54-226$ & $63-268$ & \\
\hline Albumin $-\mathrm{g} / \mathrm{dl}$ & & & & & 0.22 \\
\hline Median & 3.8 & 3.8 & 3.5 & 3.8 & \\
\hline $95 \% \mathrm{CI}$ & $3.6-4.0$ & $3.6-4.0$ & $3.3-3.7$ & $3.6-4.0$ & \\
\hline Parasite density - no. $/ \mathrm{mm}^{3}$ & & & & & $<0.001$ \\
\hline Geometric mean & 37,214 & 22,746 & 64,166 & 65,299 & \\
\hline $95 \% \mathrm{CI}$ & $26,391-52,477$ & $13,888-37,252$ & $39,155-105,153$ & $40,813-104,474$ & \\
\hline Presence of gametocytes - no. (\%) & $6(30)$ & $5(25)$ & $5(25)$ & $6(30)$ & 1.00 \\
\hline
\end{tabular}

* In Pailin, Cambodia, children older than 5 years of age were included, whereas in Wang Pha, Thailand, children 16 years of age or older and adults were enrolled. Artesunate monotherapy consisted of oral artesunate at a dose of $2 \mathrm{mg}$ per kilogram of body weight per day for 7 days. Artesunate-mefloquine therapy consisted of oral artesunate at a dose of $4 \mathrm{mg}$ per kilogram per day for 3 days, followed by mefloquine at a dose of $15 \mathrm{mg}$ per kilogram on day 3 after admission and $10 \mathrm{mg}$ per kilogram on day 4 after admission. The data are listed separately for children and adults in Table S1 in the Supplementary Appendix, available with the full text of this article at NEJM.org. To convert values for glucose to millimoles per liter, multiply by 0.05551 . To convert values for creatinine to micromoles per liter, multiply by 88.4 . To convert values for bilirubin to micromoles per liter, multiply by 17.1 . CI denotes confidence interval.

${ }^{t}$ The P value was calculated with the use of the Mann-Whitney U test. 
Table 2

Clinical and Parasitologic Responses in the Study Patients, According to Location.

\begin{tabular}{|c|c|c|c|c|c|c|c|}
\hline \multirow[t]{2}{*}{ Variable } & \multicolumn{3}{|c|}{ Wang Pha, Thailand } & \multicolumn{3}{|c|}{ Pailin, Cambodia } & \multirow{2}{*}{$\begin{array}{c}\text { P Value for Wang } \\
\text { Pha } \\
\text { vs. Pailin }\end{array}$} \\
\hline & $\begin{array}{l}\text { Artesunate } \\
\text { Monotherapy } \\
(\mathbf{N}=\mathbf{2 0})\end{array}$ & $\begin{array}{l}\text { Artesunate- } \\
\text { Mefloquine } \\
(\mathbf{N}=\mathbf{2 0})\end{array}$ & P Value & $\begin{array}{l}\text { Artesunate } \\
\text { Monotherapy } \\
(\mathbf{N}=\mathbf{2 0})\end{array}$ & $\begin{array}{l}\text { Artesunate- } \\
\text { Mefloquine } \\
(\mathbf{N}=\mathbf{2 0})\end{array}$ & P Value & \\
\hline Parasite clearance time $-\mathrm{hr}$ & & & 0.02 & & & 0.61 & $<0.001^{\dagger}$ \\
\hline Median & 54 & 48 & & 84 & 72 & & \\
\hline Interquartile range & $42-72$ & $30-54$ & & $54-96$ & $60-96$ & & \\
\hline \multicolumn{8}{|l|}{ According to parasite density at baseline } \\
\hline$<10^{5} / \mathrm{mm}^{3}$ & & & & & & & 0.006 \\
\hline No. of patients & 18 & 19 & & 11 & 15 & & \\
\hline Median & 54 & 48 & & 72 & 66 & & \\
\hline Interquartile range & $42-72$ & $30-54$ & & $48-96$ & $60-84$ & & \\
\hline$\geq 10^{5} / \mathrm{mm}_{3}$ & & & & & & & 0.003 \\
\hline No. of patients & 2 & 1 & & 9 & 5 & & \\
\hline Median & 54 & 60 & & 90 & 96 & & \\
\hline Interquartile range & $54-72$ & - & & $84-96$ & $90-108$ & & \\
\hline Time to $50 \%$ clearance of parasite density $-\mathrm{hr}$ & & & & & & 0.61 & 0.002 \\
\hline Median & 4 & 3 & & 11 & 9 & & \\
\hline Range & $1-24$ & $1-16$ & & $1-25$ & $1-22$ & & \\
\hline Time to $90 \%$ clearance of parasite density $-\mathrm{hr}$ & & & 0.40 & & & 0.89 & $<0.001$ \\
\hline Median & 12 & 11 & & 23 & 21 & & \\
\hline Range & $3-40$ & $3-27$ & & $8-39$ & $11-44$ & & \\
\hline \multicolumn{8}{|l|}{ Parasite-reduction ratio } \\
\hline After $24 \mathrm{hr}$ & & & 0.29 & & & 0.85 & $<0.001$ \\
\hline Median & 1.1 & 0.03 & & 18.7 & 13.5 & & \\
\hline Range & $0.0-54.1$ & $0.0-15.0$ & & $0.3-97.2$ & $0.9-67.6$ & & \\
\hline After $48 \mathrm{hr}$ & & & 0.08 & & & 0.52 & $<0.001$ \\
\hline Median & 0.0 & 0.0 & & 0.5 & 0.6 & & \\
\hline Range & $0.0-3.8$ & $0.0-0.5$ & & $0.0-11.4$ & $0.0-10.0$ & & \\
\hline \multicolumn{8}{|l|}{$\begin{array}{l}\text { Slope of curve for } \log _{10} \text {-normalized parasite } \\
\text { clearance }\end{array}$} \\
\hline Median & 0.10 & 0.11 & 0.21 & 0.06 & 0.05 & 0.75 & $<0.001$ \\
\hline Range & $0.05-0.15$ & $0.05-0.28$ & & $0.04-0.10$ & $0.03-0.11$ & & \\
\hline Recrudescence - no. (\%) & $2(10)$ & $1(5)$ & 1.0 & $6(30)$ & $1(5)$ & 0.09 & 0.31 \\
\hline New infection - no. (\%) & $8(40)$ & $4(20)$ & 0.30 & $1(5)$ & 0 & 1.00 & 0.001 \\
\hline $\begin{array}{c}\text { Recurrent infection with Plasmodium vivax/mixed } \\
P . \text { vivax and } P \text {. falciparum - no. }(\%)\end{array}$ & $1 / 3(5 / 15)$ & $0 / 2(0 / 10)$ & & $6 / 1(30 / 5)$ & $5 / 1(25 / 5)$ & & 0.11 \\
\hline Duration of gametocyte carriage - days $t$ & & & & & & & 0.41 \\
\hline Median & 19 & 13 & & 10 & 18 & & \\
\hline Interquartile range & $7-19$ & $1-19$ & & $7-19$ & $6-23$ & & \\
\hline
\end{tabular}




\begin{tabular}{|c|c|c|c|c|c|c|c|}
\hline \multirow[t]{2}{*}{ Variable } & \multicolumn{3}{|c|}{ Wang Pha, Thailand } & \multicolumn{3}{|c|}{ Pailin, Cambodia } & \multirow{2}{*}{$\begin{array}{c}\text { P Value for Wang } \\
\text { Pha } \\
\text { vs. Pailin }\end{array}$} \\
\hline & $\begin{array}{c}\text { Artesunate } \\
\text { Monotherapy } \\
(\mathbf{N}=\mathbf{2 0})\end{array}$ & $\begin{array}{l}\text { Artesunate- } \\
\text { Mefloquine } \\
(\mathbf{N}=\mathbf{2 0})\end{array}$ & P Value & $\begin{array}{c}\text { Artesunate } \\
\text { Monotherapy } \\
(\mathbf{N}=\mathbf{2 0})\end{array}$ & $\begin{array}{l}\text { Artesunate- } \\
\text { Mefloquine } \\
(\mathbf{N}=\mathbf{2 0})\end{array}$ & P Value & \\
\hline Time to first occurrence - days $\xi$ & & & & & & & $0.72 / /$ \\
\hline Median & 1 & 1 & & 1 & 1 & & \\
\hline Interquartile range & $1-2$ & $1-2$ & & $1-2$ & $1-2$ & & \\
\hline Time to first $24-\mathrm{hr}$ period - days $I /$ & & & & & & & $0.90 / /$ \\
\hline Median & 2 & 2 & & 2 & 1 & & \\
\hline Interquartile range & $1-2$ & $1-2$ & & $1-3$ & $1-2$ & & \\
\hline
\end{tabular}

* Artesunate monotherapy consisted of oral artesunate at a dose of $2 \mathrm{mg}$ per kilogram of body weight per day for 7 days. Artesunate-mefloquine therapy consisted of oral artesunate at a dose of $4 \mathrm{mg}$ per kilogram per day for 3 days, followed by mefloquine at a dose of $15 \mathrm{mg}$ per kilogram on day 3 after admission and $10 \mathrm{mg}$ per kilogram on day 4 after admission.

${ }^{\dagger} \mathrm{P}=0.008$ after adjustment for baseline parasite load.

${ }^{*}$ Duration of carriage is reported only for patients for whom blood specimens were positive for gametocytes at any time.

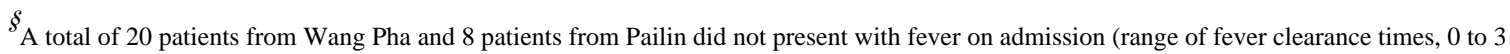
days).

II A total of 11 patients from Wang Pha and 5 patients from Pailin did not have fever for at least the first 24 hours after admission (range of fever clearance times, 0 to 5 days).

/The P value was calculated with the Wilcoxon-Breslow test for equality of survivor functions; there were no significant differences between treatment groups at either site. 
Table 3

Results of Noncompartmental Analysis of First-Dose Pharmacokinetics, According to Study Drug. *

\begin{tabular}{|c|c|c|c|c|c|c|c|}
\hline \multirow[t]{2}{*}{ Variable } & \multicolumn{2}{|c|}{ Wang Pha, Thailand } & \multicolumn{2}{|c|}{ Pailin, Cambodia } & \multicolumn{3}{|c|}{ P Value for Wang Pha vs. Pailin } \\
\hline & $\begin{array}{l}\text { Artesunate } \\
\text { Monotherapy } \\
(\mathbf{N}=\mathbf{2 0})\end{array}$ & $\begin{array}{l}\text { Artesunate- } \\
\text { Mefloquine } \\
\quad(\mathbf{N}=\mathbf{2 0})\end{array}$ & $\begin{array}{l}\text { Artesunate } \\
\text { Monotherapy } \\
(\mathbf{N}=\mathbf{2 0})\end{array}$ & $\begin{array}{l}\text { Artesunate- } \\
\text { Mefloquine } \\
\quad(\mathbf{N}=19)\end{array}$ & $\begin{array}{c}\text { Both } \\
\text { Treatment } \\
\text { Groups }\end{array}$ & $\begin{array}{l}\text { Artesunate } \\
\text { Monotherapy }\end{array}$ & $\begin{array}{l}\text { Artesunate- } \\
\text { Mefloquine }\end{array}$ \\
\hline \multicolumn{8}{|c|}{ Dose $(\mathrm{mg} / \mathrm{kg})$} \\
\hline Median & 2.03 & 4.03 & 2.01 & 3.95 & & 0.41 & 0.81 \\
\hline Range & $1.81-2.14$ & $3.85-4.09$ & $1.83-2.33$ & $3.80-4.17$ & & & \\
\hline \multicolumn{8}{|c|}{ Artesunate } \\
\hline \multicolumn{8}{|c|}{$\begin{array}{l}\text { Maximum plasma drug } \\
\text { concentration (nM) }\end{array}$} \\
\hline Median & 444 & 522 & 702 & 822 & & 0.47 & 0.09 \\
\hline Range & $83-1300$ & $120-3720$ & $79-2540$ & $97-4590$ & & & \\
\hline \multicolumn{8}{|c|}{$\begin{array}{l}\text { Time to maximum } \\
\text { concentration }(\mathrm{hr})\end{array}$} \\
\hline Median & 0.38 & 0.50 & 0.50 & 1.00 & 0.002 & & \\
\hline Range & $0.25-0.98$ & $0.25-3.00$ & $0.25-2.00$ & $0.25-2.00$ & & & \\
\hline \multicolumn{8}{|c|}{$\begin{array}{l}\text { Terminal elimination half- } \\
\text { life (min) }\end{array}$} \\
\hline Median & 22.3 & 34.6 & 17.2 & 17.4 & 0.17 & & \\
\hline Range & $8.6-180.0$ & $8.0-105.0$ & $7.7-82.4$ & $9.4-62.7$ & & & \\
\hline \multicolumn{8}{|c|}{$\mathrm{AUC}_{0-24}(\mathrm{hr} \times \mathrm{nM})$} \\
\hline Median & 333 & 616 & 450 & 880 & & 0.14 & 0.01 \\
\hline Range & $167-602$ & $227-1320$ & $163-969$ & $345-2090$ & & & \\
\hline \multicolumn{8}{|c|}{ Dihydroartemisinin } \\
\hline \multicolumn{8}{|c|}{$\begin{array}{l}\text { Maximum plasma drug } \\
\text { concentration }(\mathrm{nM})\end{array}$} \\
\hline Median & 3020 & 4190 & 2820 & 5590 & & 0.50 & 0.11 \\
\hline Range & $523-5690$ & $1650-11,300$ & $543-10,600$ & $2950-17,900$ & & & \\
\hline \multicolumn{8}{|c|}{$\begin{array}{l}\text { Time to maximum } \\
\text { concentration (hr) }\end{array}$} \\
\hline Median & 1.00 & 1.01 & 1.00 & 1.50 & 0.09 & & \\
\hline Range & $0.48-2.98$ & $0.48-3.00$ & $0.50-4.00$ & $0.42-3.00$ & & & \\
\hline \multicolumn{8}{|c|}{$\begin{array}{l}\text { Terminal elimination half- } \\
\text { life (min) }\end{array}$} \\
\hline Median & 42.3 & 50.9 & 50.1 & 45.9 & 0.26 & & \\
\hline Range & $23.8-94.6$ & $30.1-70.8$ & $28.1-95.1$ & $32.4-94.3$ & & & \\
\hline \multicolumn{8}{|c|}{$\mathrm{AUC}_{0-24}(\mathrm{hr} \times \mathrm{nM})$} \\
\hline Median & 4600 & 10,400 & 4860 & 14,500 & & 0.34 & 0.04 \\
\hline Range & $1940-9330$ & $4770-20,000$ & $1920-15,400$ & $6540-19,900$ & & & \\
\hline
\end{tabular}

* Artesunate monotherapy consisted of oral artesunate at a dose of $2 \mathrm{mg}$ per kilogram of body weight per day for 7 days. Artesunate-mefloquine therapy consisted of oral artesunate at a dose of $4 \mathrm{mg}$ per kilogram per day for 3 days, followed by mefloquine at a dose of $15 \mathrm{mg}$ per kilogram on 
day 3 after admission and $10 \mathrm{mg}$ per kilogram on day 4 after admission. $\mathrm{AUC}_{0}-24$ denotes the area under the plasma concentration-time curve after the first dose. 